\title{
Psychosocial adjustment in preschool children with atopic eczema
}

\author{
L R Daud, M E Garralda, T J David
}

\begin{abstract}
Atopic eczema is a chronic skin disorder that is most common in early childhood, an important stage in the child's social and emotional development. The psychiatric adjustment and mother-child attachment in 30 preschool children with severe atopic eczema was compared with 20 matched controls. Patients with eczema had a significant increase in behaviour symptoms, $7 / 30(23 \%) v 1 / 20$ $(5 \%)$; with significant excess of dependency/clinginess, $15 / 30(50 \%) v 2 / 20(10 \%)$; fearfulness, $12 / 30(40 \%) v 2 / 20(10 \%)$; and sleep difficulty, $19 / 30(63 \%) v 9 / 20(45 \%)$, but there was no significant difference between the two groups in the security of attachments, 25/29 (86\%) v 14/20 (70\%). Significantly fewer mothers of children with atopic eczema were in outside employment, $8 / 29(27 \%) v 13 / 20(65 \%)$, or felt supported socially, 10/29 (34\%) $v$ 13/20 $(65 \%)$. Significantly more of them, $9 / 30$ $(30 \%) v 1 / 20(5 \%)$, felt particularly stressed in relation to their parenting and less efficient in their disciplining of the affected child. In spite of this and at variance with earlier reports in the literature, they did not display negative attitudes towards their child. On the contrary mothers had a positive empathic attitude towards the child, $7 / 14(50 \%) v 2 / 16(12 \%)$. Child behaviour problems, 7/14 (50\%) $v$ $2 / 16(12 \%)$, and maternal distress, $12 / 14$ $(85 \%) v 5 / 16(31 \%)$, were significantly more common in the more severely affected children. Minor behaviour problems and parenting distress are important features of severe atopic eczema in early childhood but atopic eczema does not lead to insecurity of the mother-child attachment.
\end{abstract}

(Arch Dis Child 1993; 69: 670-676)

University of Manchester, Department of Child Psychiatry

L R Daud

M E Garralda

Department of Child Health

T J David

Correspondence to: Dr L R Daud, McGuiness Unit, Prestwich Hospital, Bury New Road, Prestwich, Manchester M25 7BL.

Accepted 15 September 1993
Atopic eczema is a common skin disorder of early childhood affecting about $10 \%$ of all children. In the majority of children the condition is mild but in a small number it can be severe and distressing for both the child and the parents.

The main symptom of atopic eczema is scratching which damages the skin, often causes bleeding, and irritates onlookers. Extra care, such as distraction, parental rubbing, or the use of cotton tubular bandage are required to minimise skin damage. Further supervision is required for the frequent application of topical treatment and the avoidance of trigger factors such as foods, pets, woollen clothes, soap, and enzyme containing washing powder. Families may be restricted when eating in restaurants or going on holiday, and parents describe a general burden of extra care. Children may be restricted in mixing with their peers, going to parties, or sleeping at friends' houses and are often cruelly teased by the use of unpleasant nicknames. Additional disadvantages include short stature ${ }^{12}$ and the use of bandages. Atopic eczema is particularly common in young children under 5 years of age. ${ }^{34}$ It is therefore at its most prevalent and troublesome at an important time for the child's emotional and social development. There has, however, been very little research into the psychiatric adjustment of young children with eczema. Early psychodynamic writings emphasised the relationship problems that were often seen as part of the condition. The key emotional conflict was seen as a hostile dependent relationship with the mother and the situation was described as a continuous 'battle of wills' between a tired, irritable, overwrought, poorly sleeping mother, and an anxious, insecure child with many fears and much wilful, aggressive behaviour. ${ }^{5}$ In older children a clinical impression has been that atopic eczema lowers self image, self esteem and confidence, particularly at times of life when the individual would normally be beginning to socialise. ${ }^{6}$

Recent community based surveys of large samples of children have shown an association between atopic eczema and fearfulness and sleeping problems. ${ }^{3}$ As with other chronic conditions of childhood, it is likely that fearfulness and other problems are more handicapping in the most severely affected children but there has been no systematic work to examine the way in which severe eczema affects young children's social development and psychiatric adjustment or parental coping. A better understanding of these factors is important because it is probable that psychosocial aspects are of relevance in the handling of the atopic eczema itself. There are indications that stress may exacerbate symptoms of atopic eczema, ${ }^{78}$ that styles of family interaction are linked to symptomatology in the child, ${ }^{9}$ and that troubling symptoms such as scratching can be predicted from parental responses, ${ }^{10}$ and respond to behavioural treatments with consequent improvement on the atopic eczema itself. ${ }^{11-13}$ Observational case studies have been reported where treatments aimed at improving the parent-child relationship have resulted in improvements in both skin and behavioural symptoms. ${ }^{14}$

We have compared children with atopic 
Table 1 Demographic data; figures are number (\%) except for age

\begin{tabular}{llc}
\hline & $\begin{array}{c}\text { Atopic eczema } \\
(n=30)\end{array}$ & $\begin{array}{c}\text { Controls } \\
(n=20)\end{array}$ \\
\hline $\begin{array}{l}\text { Sex } \\
\text { Boys }\end{array}$ & $19(63)$ & $12(60)$ \\
$\begin{array}{l}\text { Girls } \\
\text { Mean (SD) age in months }\end{array}$ & $\begin{array}{l}11(37) \\
(n=29)\end{array}$ & $\begin{array}{c}8(40) \\
(n=20)\end{array}$ \\
$\begin{array}{c}\text { Social class } \\
\text { I and II (professional and } \\
\text { intermediate occupations) }\end{array}$ & $\begin{array}{l}12(41) \\
10(35)\end{array}$ & $\begin{array}{l}8(40) \\
7(35)\end{array}$ \\
$\begin{array}{l}\text { III (skilled) } \\
\text { IV, V, and VI (partly skilled, } \\
\text { unskilled, and unemployed) }\end{array}$ & $7(25)$ & $5(25)$ \\
$\begin{array}{c}\text { Parental status: living with two } \\
\text { natural parents }\end{array}$ & $25(86)$ & $15(75)$ \\
$\begin{array}{c}\text { Maternal employment: in full or } \\
\text { part time work }\end{array}$ & $8(27 \cdot 6)$ & $13(65)$ \\
\hline
\end{tabular}

^Fisher's exact test, $\mathrm{p}<0.05$.

eczema with a matched control sample of healthy children and used standardised instruments to measure the psychiatric and social adjustment of the children, the styles of parenting and family stress, and looked at associations between severity of the eczema and the psychosocial variables.

\section{Patients and methods}

The study was carried out between January 1989 and February 1990. All patients were attending the department of child health at Booth Hall Children's Hospital. To exclude very mild cases we studied only those children in whom at the time of the first attendance at hospital the eczema affected at least $10 \%$ of the skin surface area, and in whom the eczema warranted outpatient hospital attendance every three months. The parents of all children aged 18-48 months who met the criteria were invited to participate in the study. A total of 36 subjects were eligible and the parents of 30 agreed to take part.

A control group of 20 children matched for age, sex, socioeconomic status and parental marital state, were selected for this study. None of the children had any chronic physical disorder. An attempt was made to control for maternal working status, but it proved difficult to find families where the mother did not go out to work (see results). It was not possible to find a control sample from any single source because of the need to match for various characteristics. The controls came from a local community health clinic and a day nursery, and of 27 mothers who were approached, 20 $(74 \%)$ agreed to take part in the study. The main demographic features in the eczema and control group are given in table 1 .

All interviews and assessments were performed by LRD. The child's psychiatric adjustment was assessed from interviews with the mothers using the behaviour screening questionnaire. ${ }^{15}$ This is a standardised semistructured interview that explores 12 areas of problem behaviours and has been found to be valid and reliable to assess behavioural disturbance in 3 year olds. ${ }^{16}$ The presence and severity of symptoms in each area are scored and summed up to give a total score. In 3 year olds a score of 10 or more indicates a high risk for psychiatric disturbance. ${ }^{16}$ The scoring needed to be modified for this study because of the inclusion of younger children for whom two items (soiling and worries) were removed. Accordingly the global score for the younger children was adjusted to a cut off point of 9 . For the older children the recommended cut off point of 10 was used. ${ }^{16} 17$ The validity of these pass scores was ascertained by comparing them with psychiatric assessment, based on global clinical ratings made by the interviewer based on the interview information from both groups. Our revised cut off point gave a sensitivity of $71 \%$ and a specificity of $86 \%$.

We used the Ainsworth strange situation procedure $^{18}$ to assess the security of attachment as a measure of social development. The procedure has been extensively used in a variety of conditions and age groups to assess the quality of mother-child attachment. ${ }^{19}$ For this study the three episode version of the procedure was used. ${ }^{20}$

Videotaped interviews were taken of the strange situation and ratings made on interactive behaviours, which includes proximity seeking, contact maintaining, avoidance, resistance and distance interaction. On the basis of the assessments, children were classified into securely and insecurely avoidant or insecurely ambivalent. ${ }^{18}$ The reliability of our attachment ratings was examined by comparing the assessments of two observers (LRD and MEG). There was complete agreement for 10 randomly selected children as to the security of attachment. When children were subdivided to insecurely avoidant and insecurely ambivalent, the agreement between the two observers was $90 \%$.

In addition to the classification of children into securely and insecurely attached, we used the attachment situation to devise further scores to assess in a qualitative way the extent of the efforts made by the child and his/her mother to keep in physical contact as we called this, the 'contact keeping score'. This was done by adding up the scores of proximity seeking and contact maintaining behaviour and subtracting from it the score of avoidant and resistant behaviour. We also recorded the time the children spent in direct physical contact with their mothers.

We developed a parenting evaluation interview based on previous instruments. ${ }^{21-23}$ This was a semistructured interview based on six areas of daily activities (eating, sleeping, supervision and play, attention seeking behaviour, temper and naughtiness, and crying). We asked questions to evaluate styles and attitudes of parenting and scored the answers in the following domains: supervision; regularity of care; positive styles of discipline such as encouraging, persuading, or comforting; negative styles of discipline such as shouting, threatening, punishing, and giving in to the child's demands; effectiveness of discipline; maternal distress experienced; maternal tiredness/fed up; positive comments expressed during the interview; negative comments expressed during the interview and overall warmth expressed during the interview.

We devised the 'quality of parenting' score by comparing the individual scores of each 
variable with the median score for that variable from the control data. We allocated one point whenever a score differed from the median in a direction indicating poorer parenting (for example more shouting or less encouraging) so that a 'quality of parenting' score ranging between 0 to 10 was calculated for each subject. We arbitrarily interpreted scores 0 to 5 as representing a good quality of parenting and 6 to 10 as representing poor quality of parenting. The reliability of these assessments were examined by test-retest interviews which were carried out within 4-6 weeks in 10 subjects. We examined the agreement for good and poor parenting from the two tests, and the resulting agreement in terms of the final subdivision of parenting into good and poor was $80 \%$.

Current stresses and supports for the parents in a number of psychosocial areas (occupation, finance, housing, marriage, social life, and children) were assessed with the social stress and support interview. ${ }^{24}$ Current mental distress in mothers was assessed using the general health questionnaire. ${ }^{25} \mathrm{We}$ also asked mothers to indicate whether they thought their children could be described temperamentally as generally difficult or easy. We asked mothers whether they regarded their child as easily upset or placid, as affectionate or not, as regular or irregular, as easily adaptable or not, and as usually happy or unhappy. A developmental assessment of the child was carried out using the Denver developmental screening test. ${ }^{26}$ Details of the atopic eczema and its impact on the family were collected from the interviews with the mothers. The parents' occupation was recorded and used to determine social class, as defined by the registrar general. ${ }^{27}$ Mothers were asked whether they felt they had had to give up a lot for their child's sake, whether their relationship with their husband/other children or their family life had been altered, and whether their own outside interests had been altered by their child's atopic eczema.

\section{Results}

Although at the time of the first visit to outpatients all children had been severely affected by eczema, by the time of the study $14 / 30$ $(46 \%)$ had over $10 \%$ skin area affected by eczema. In the rest the surface area affected had fallen to less than $10 \%$. The redness of the skin lesions was severe in $2 / 30(6 \%)$ of children, moderate in $8 / 30(26 \%)$, and mild in $20 / 30$ $(67 \%)$. Half the children had been admitted to hospital at some point during their illness, and $3 / 30(10 \%)$ had been admitted more than twice. Fifteen children were on some dietary restrictions and another $3 / 30(10 \%)$ had received an elemental diet. ${ }^{28}$ Fifteen children were receiving trimeprazine tartrate at bedtime as a sedative, and another child received it also during the day. In answer to the question 'How severe the problem was ...', the atopic eczema was regarded by mothers as a severe problem in 15 children, a moderate problem in 12 , and a minimal problem in three.
Table 2 Behavioural screening questionnaire: age adapted

\begin{tabular}{lll}
\hline & $\begin{array}{l}\text { Atopic } \\
\text { eczema } \\
(n=30)\end{array}$ & $\begin{array}{l}\text { Controls } \\
(n=20)\end{array}$ \\
\hline Mean (SD) scores & $7 \cdot 4(3 \cdot 5)$ & $4 \cdot 8(2 \cdot 9)$ \\
No (\%) with high scores & $9(30)$ & $2(10)$ \\
No (\%) clinical 'cases' $\dagger$ & $7(23)$ & $1(5)$
\end{tabular}

^By $t$ test, $\mathrm{p}=0 \cdot 01$. †Fisher's exact test, $\mathrm{p}=0.08$.

For clinical case definition see text.

The results of the behavioural screening questionnaire are shown in table 2 . Children with atopic eczema had more psychopathology as shown by statistically significant higher questionnaire total scores. In addition, three times as many atopic eczema children as controls scored above the cut off points for disturbance (that is high questionnaire scores) and more were rated as behaviourally disturbed on the clinical assessment by the interviewer. The latter was not statistically significant. Of those disturbed, $6 / 30(20 \%)$ were mild and $1 / 30(3 \%)$ was severe. The severity rating was based on the frequency and duration of the problem behaviour as well as the amount of suffering apparent within the child, the degree to which it affected relationships with adults and children, and the child's ability for play and independence. ${ }^{15}$

Details of the psychiatric symptomatology are shown in table 3 . In children with atopic eczema the most striking behavioural disturbance was clinginess and dependency (that is children who were upset if left and took some time to get over it). However, this was not severe in intensity and only one child showed marked clinginess. Attention seeking behaviour was common in both groups but tended to be more severe in the atopic eczema group. 'Mild' fearfulness was more commonly reported in the atopic eczema group and was statistically significant. This indicated that a child was somewhat afraid or uncertain about approaching at least 3-5 feared objects/persons and requiring reassurance or that he/she was markedly frightened of 1-2 objects/persons. Twenty five out of 30 (83\%) children in the atopic eczema group who had problems in this area had at least one marked fear. The most common fears were of strangers $6 / 30(20 \%)$, doctors $6 / 30(20 \%)$, of bath or water and of loud noise $5 / 30(16 \%)$. Sleep problems (that is waking at night three times a week or more) were twice as common in the eczema group.

Table 3 Child psychiatric adjustment using the behavioural screening questionnaire: symptomatology; figures are number (\%)

\begin{tabular}{lcc}
\hline & $\begin{array}{c}\text { Atopic } \\
\text { eczema } \\
(n=30)\end{array}$ & $\begin{array}{c}\text { Controls } \\
(n=20)\end{array}$ \\
\hline $\begin{array}{l}\text { Clingy/dependent } \\
\text { Mild } \\
\text { Marked }\end{array}$ & $14(46)$ & $2(10)$ \\
$\begin{array}{l}\text { Attention seeking } \\
\text { Mild } \\
\quad \text { Marked }\end{array}$ & $1(3)$ & 0 \\
$\begin{array}{l}\text { Fearst } \\
\quad \text { Mild }\end{array}$ & $17(56)$ & $12(60)$ \\
$\begin{array}{l}\text { Sleep waking at night } \\
\text { Mild } \\
\text { Marked }\end{array}$ & $10(30)$ & $3(15)$ \\
\hline
\end{tabular}

${ }^{\star} \mathrm{p}<0.05 ; \mathrm{tp}<0.05$. 
Table 4 Attachment (Ainsworth situation)

\begin{tabular}{|c|c|c|}
\hline & $\begin{array}{l}\text { Atopic } \\
\text { eczema } \\
(n=29)\end{array}$ & $\begin{array}{l}\text { Controls } \\
(n=20)\end{array}$ \\
\hline \multicolumn{3}{|l|}{ Attachment (No (\%)) } \\
\hline $\begin{array}{l}\text { Secure } \\
\text { Insecure }\end{array}$ & $\begin{array}{r}25(86) \\
4(13)\end{array}$ & $\begin{array}{r}14(70) \\
6(30)\end{array}$ \\
\hline \multicolumn{3}{|l|}{ 'Contact keeping' score } \\
\hline $\begin{array}{l}\text { Mean (SD) } \\
\text { Median }\end{array}$ & $\begin{array}{l}3 \cdot 7(4 \cdot 3) \\
4\end{array}$ & $\begin{array}{l}1 \cdot 8(4 \cdot 3) \\
3\end{array}$ \\
\hline \multicolumn{3}{|l|}{ Time in contact $(\mathrm{sec})$} \\
\hline \multicolumn{3}{|l|}{ Episode 1: preseparation } \\
\hline $\begin{array}{l}\text { Mean (SD́) } \\
\text { Median }\end{array}$ & $\begin{array}{l}17 \cdot 1(34 \cdot 4) \\
28\end{array}$ & ${ }_{23}^{8 \cdot 5(18)}$ \\
\hline \multicolumn{3}{|l|}{ Episode 3: reunion } \\
\hline Mean (SD) & $47 \cdot 8(60)$ & $28 \cdot 9(40)$ \\
\hline $\begin{array}{l}\text { Median } \\
\text { All } 3 \text { min + in contact (No (\%)) }\end{array}$ & $\begin{array}{l}20 \\
6(20)\end{array}$ & 16 \\
\hline
\end{tabular}

Definition of time in contact for episode 1 and 3, see text.

Children with atopic eczema did not have statistically significant greater problems in terms of other behavioural disturbance such as sleeping in the parents' bed, eating problems, difficulties with activity and concentration, tantrums and manageability, mood changes, nor in relationships with siblings and peers.

The mothers' views on the children's usual behavioural styles were in keeping with the symptom descriptions given in the behavioural screening questionnaire. Significantly more mothers of children with atopic eczema described them as generally difficult $(20 \%)$ and none of the controls (Fisher's exact test, $p=0.05$ ). The only temperamental subcategory where eczema children were regarded differently from controls was in adaptability: $13 / 30(43 \%)$ v $2 / 30(10 \%)$ of controls were seen as poorly adaptable (Fisher's exact test, $\mathrm{p}<0.05$ ).

There was no significant difference between the two groups in the developmental assessment, with $24 / 28(85 \%)$ of these with atopic eczema and $17 / 20(85 \%)$ children in the control group scoring as within the normal range on the Denver developmental screening test.

\section{ATTACHMENT RATINGS}

The data collected from one atopic eczema case was incomplete as the family moved out of the area. Ratings made on the basis of the Ainsworth attachment situation are shown in table 4. There was no statistical significance between the groups. Children with atopic eczema scored higher on the contact keeping score with the mother and they spent more time in physical contact with her both in the preseparation (episode 1) and reunion

Table 5 Maternal stress measured by social stress and support interview (SSSI) and general health questionnaire (GHQ); figures are number (\%) except for $G H Q$ scores

\begin{tabular}{lll} 
& $\begin{array}{l}\text { Atopic } \\
\text { eczema } \\
(n=29)\end{array}$ & $\begin{array}{l}\text { Controls } \\
(n=20)\end{array}$ \\
\hline SSSI high psychosocial stress $^{\star}$ & $17(58)$ & $6(30)$ \\
Highly stressed about child $^{\star}$ & $15(51)$ & $4(20)$ \\
SSSI low support in social life & $19(65)$ & $7(35)$ \\
& $(n=25)$ & $(n=20)$ \\
Mean (SD) GHQ scores & $2 \cdot 6(4 \cdot 2)$ & $0 \cdot 5(1 \cdot 5)$ \\
High scores on GHQ & $6(24)$ & $1(5)$ \\
\hline
\end{tabular}

^Fisher's exact test, $\mathrm{p}<0.05$ (episode 3), but there was wide variation in these scores as shown by the higher standard deviations and the difference failed to reach statistical significance. Six of $29(20 \%)$ of the children with atopic eczema spent the three minutes assessment period during the reunion episode in direct physical contact with the mother as opposed to only $1 / 20(5 \%)$ of the control group, but this finding was not statistically significant $\left(\chi^{2}=4 \cdot 98, \mathrm{df}=2, \mathrm{p}=0.08\right)$.

\section{MATERNAL STRESS AND PARENTING}

Levels of current mental distress in the parents as measured by scores on the general health questionnaire showed higher distress scores in the eczema group and more mothers with scores above the cut off point (see table 5). However, this difference was not statistically significant (Fisher's exact test, $\mathrm{p}=0.08$ ). We also investigated current psychosocial stress and support for the mothers at the time of assessment by comparing the two groups on the scores from the social stress and support interview (see table 5). There were statistically significant differences between the two groups in the global stress levels reported, with nearly twice as many mothers in the eczema group reporting being highly stressed. When we examined the individual areas of psychosocial stress, only stress related to the index child differentiated the two groups, with more mothers feeling highly stressed about their child with atopic eczema: 15/29 (51\%) compared with $4 / 20(20 \%)$ of the control group. Although the two groups were comparable for total levels of psychosocial support, there were differences in the two groups in the support derived from social life; more mothers in the eczema group, $19 / 29(65 \%)$ compared with $7 / 20(35 \%)$ of the control group, indicated low levels of support in this area (Fisher's exact test, $\mathrm{p}<0.05$ ).

The parenting evaluation interview identified differences in the global quality of parenting between the two groups. A higher score meant poorer parenting. Table 6 shows that mothers in the eczema group had statistically significantly poorer parenting mean scores. This did not indicate differences in the care provided, which was judged to be adequate in

Table 6 Parenting scores

\begin{tabular}{|c|c|c|}
\hline & $\begin{array}{l}\text { Atopic } \\
\text { eczema } \\
(n=30)\end{array}$ & $\begin{array}{l}\text { Controls } \\
(n=20)\end{array}$ \\
\hline \multicolumn{3}{|l|}{ Global quality ${ }^{\star}$} \\
\hline Mean (SD) & $3.9(1.8)$ & $2 \cdot 8(2)$ \\
\hline Good qualityt & 17 & 17 \\
\hline Poor quality & 13 & \\
\hline \multicolumn{3}{|l|}{ Supervision (No (\%)) } \\
\hline \multirow{2}{*}{\multicolumn{3}{|c|}{ Regularity (No (\%)) }} \\
\hline & & \\
\hline Adequate & $29(96)$ & $17(85)$ \\
\hline $\begin{array}{l}\text { Discipline effectiveness (No (\%)) } \\
\text { Mean (SD) } \ddagger\end{array}$ & $\begin{array}{l}19(63) \\
2.5(2 \cdot 4)\end{array}$ & $\begin{array}{l}17(85) \\
1.6(2.6)\end{array}$ \\
\hline \multicolumn{3}{|l|}{ Mean (SD) scores for discipline style } \\
\hline Distract/comfort & $6 \cdot 3(2 \cdot 2)$ & $5 \cdot 4(2 \cdot 0)$ \\
\hline Shout/threaten & $4.5(1.9)$ & $4 \cdot 7(1 \cdot 7)$ \\
\hline Give in ${ }^{\star}$ & $5 \cdot 5(2 \cdot 6)$ & $4 \cdot 0(1 \cdot 4)$ \\
\hline Persuade & $4 \cdot 3(2 \cdot 1)$ & $3.8(1.7)$ \\
\hline Ignore & $3 \cdot 1(2 \cdot 0)$ & $2 \cdot 7(1.7)$ \\
\hline Punish & $2 \cdot 0(1.5)$ & $1.7(1.4)$ \\
\hline
\end{tabular}

$\star$ By $t$ test, $\mathrm{p}<0.05$.

tFisher's exact test, $\mathrm{p}<0.05$.

†Mann-Whitney U, $\mathrm{p}<0.05$. 
Table 7 Maternal attitude towards index child (questionnaire); figures are number (\%)

\begin{tabular}{lcc}
\hline & $\begin{array}{c}\text { Atopic } \\
\text { eczema } \\
(n=25)\end{array}$ & $\begin{array}{c}\text { Controls } \\
(n=20)\end{array}$ \\
\hline $\begin{array}{l}\text { Stressed/strained } \\
\quad \text { Mild }\end{array}$ & $12(48)$ & $2(10)$ \\
$\begin{array}{l}\text { Marked } \\
\text { Felt sorry for child }\end{array} \quad$ & $4(16)$ & 0 \\
$\quad \begin{array}{l}\text { Mild } \\
\text { Marked }\end{array}$ & $11(44)$ & $1(5)$ \\
$\begin{array}{l}\text { Accepting the child } \\
\text { Mild }\end{array}$ & $4(16)$ & 0 \\
Marked & $1(4)$ & $1(5)$ \\
\hline
\end{tabular}

Mild=some of the time; marked =most of the time

${ }^{\star} \chi^{2} \mathrm{p}=0.03, \mathrm{df}=2$.

terms of supervision and regularity in most cases in both groups. The main difference was in the results of the mothers' attempts to discipline the children, which were less effective in the atopic eczema group in whom the mothers tended to give in significantly more to their children than did mothers of controls. The parenting evaluation interview was also used to assess maternal attitudes towards parenting the index child. Significantly more mothers in the atopic eczema group reported feeling distressed: $9 / 30(30 \%)$ compared with $1 / 20(5 \%)$ of the control group $\left(\chi^{2}=5 \cdot 69, \mathrm{df}=2, \mathrm{p}=0 \cdot 05\right)$. Mothers of children with atopic eczema were more likely to feel tired and 'fed up': 12/30 $(40 \%)$ compared with $2 / 20(10 \%)$ of the control group $\left(\chi^{2}=3.97, \mathrm{df}=1, \mathrm{p}<0.05\right)$. However, there were no significant differences in the affective response to the child as measured by warmth expressed by mothers of children with atopic eczema when talking about their child, $22 / 30(73 \%) v 17 / 20(85 \%)$ in the control group, and the number of positive, $18 / 30(60 \%) \vee 13 / 20(65 \%)$, and negative, $11 / 30(36 \%)$ v 4/20 (20\%), comments made. These reports were confirmed from the self rating maternal attitude questionnaire which we had asked the mothers to complete, using a five point scale to indicate the degree to which various attitudes applied in their relationship with their child. Table 7 shows that, although significantly more mothers of children with eczema reported being stressed about the child, they also reported empathic feelings in the sense of feeling sorry for the child and the level of acceptance was comparable with that of controls. Moreover, these mothers failed to report disagreement with their spouses in terms of handling and punishment any more than mothers of the control group.

The areas of parenting which led to mothers of children with atopic eczema reporting high levels of distress were feeding the child, 7/30 $(23 \%) v 0 / 20$ in the control group, and attention seeking behaviour, $6 / 30(20 \%) v 0 / 20$ (Fisher's exact test, $p<0.05$ ). There were no differences between the mothers of patients and controls in the distress experienced over supervision of the child, his/her play, naughtiness and tempers, crying, or sleeping.

Twenty out of $30(66 \%)$ of the mothers felt that the atopic eczema had had an influence on their marriage and this effect was more likely to be negative $13 / 30(43 \%)$ than positive $6 / 30$
(20\%), or mixed $3 / 30(10 \%)$. Most mothers $26 / 30(86 \%)$ reported an effect on family life, usually detrimental $25 / 30(83 \%$ ), and $20 / 30$ $(66 \%)$ felt it had had a substantial effect on their parenting of the child.

\section{ASPECTS OF ILLNESS AND PSYCHOSOCIAL} ADJUSTMENT

We considered whether the severity of the condition was associated with risk for child and family disturbance and found a link between severity of the eczema at the time of assessment and both child psychiatric morbidity and maternal distress. Seven out of $14(50 \%)$ of the children severely affected $(10 \%$ or more surface area) with eczema had behavioural screening questionnaire scores above cut off points, indicating psychiatric morbidity, as opposed to $2 / 16(12 \cdot 5 \%)$ of the less severely affected children, a statistically significant difference $\left(\chi^{2}=5, \mathrm{df}=1, \mathrm{p}<0.05\right.$ before Yates's correction $)$ or $\left(\chi^{2}=3.37, \mathrm{df}=1, \mathrm{p}=0.06\right.$ after Yates's correction). Similarly, high maternal distress (the overall stress experienced in different areas of their lives) as defined in the social stress and support interview was reported by $12 / 14(85 \%)$ of the severely affected children, but only $5 / 16(31 \%)$ of the less severely affected children, a difference which was statistically significant $\left(\chi^{2}=6.93\right.$, $\mathrm{df}=1, \mathrm{p}<0.01$ ).

Because of the clinical importance of scratching and its social implications, we examined whether it was related to psychosocial morbidity. We compared the 15 children where scratching was regarded by mothers as a severe problem with the other 15 children with atopic eczema. No statistical significant associations were found with child morbidity nor with levels of maternal distress. Mothers of children where scratching was a problem reported more giving in in their disciplining of the children, and this was not statistically significant.

\section{Discussion}

Our results show a statistical significant excess of child behavioural problems, family disruption, and stressed parenting in children with atopic eczema that was sufficiently severe to warrant regular clinic attendance. However, the majority of children with eczema were well adjusted psychiatrically, and we failed to confirm previously reported negative maternal attitudes towards the child or insecure attachments. The higher social classes (that is parents with professional and intermediate occupations) were over represented in our study, and this could have reduced the likelihood of finding behavioural problems in the children and negative attitude of the mothers.

About a third of the children with eczema had behavioural screening questionnaire scores above morbidity levels, a statistically significant higher rate than in controls or in general population samples. ${ }^{1529}$ The frequency of disturbance in children with eczema was comparable with those in other severe chronic 
physical problems of childhood. ${ }^{30}$ Thus atopic eczema is a risk factor for the development of behaviour problems in children, and our data reinforce the importance of taking into account the severity of a physical illness when assessing the psychopathology associated with childhood illness.

We failed to confirm earlier clinical impressions of an association between atopic eczema and irritable and aggressive behaviour. ${ }^{5}$ The psychological symptoms found to be in excess in the eczema group were rather in the area of dependency, fearfulness, and wakefulness. These symptoms were similar to the psychological features that were previously found to be associated with atopic eczema in a community sample. ${ }^{3}$

In contrast, the behavioural symptoms that are most prevalent in 3 year olds in community studies, ${ }^{16}$ and that predict continuation of difficulties into later childhood, are of a quite different nature. They are most notably features of over activity, attention seeking behaviour, disobedience, and being generally difficult to manage. This fact plus our finding that most disorders in children with eczema in our sample were mild in nature, and that their presence was related to the severity of the eczema itself, indicates that the emotional disturbance in most children with atopic eczema is not likely to be severe, and is likely to be temporary, and is closely related to the physical state.

Our results show that family life and parenting were markedly disrupted by having a child with eczema. Parents commonly reported feeling highly stressed in relation to parenting their ill child. Mothers were less frequently in outside employment and they reported less support from their social life, most notably the fact that friends were unwilling or frightened to babysit for them and that they had few if any friends. The strain and practical demands of the child's condition thus had an adverse effect on the parental social functioning.

The decreased social activity by mothers may in turn adversely affect their parenting. The paediatric team may be able to assist in this area by becoming aware of any existing strains and by considering ways of helping mothers increase their satisfaction with social contacts, perhaps by promoting parenting groups where mothers can derive support from each other.

In spite of these strains mothers of patients did not differ from control mothers in important aspects of parenting such as the provision of adequate supervision and regularity, nor, and at variance with earlier reports in the literature, ${ }^{5}$ did they display negative attitudes towards their child. In fact they showed empathic feelings towards them and maternal stress was much more prevalent than childhood behavioural problems, indicating that mothers were able to contain their distress and provide appropriately for the needs of the child. This indicates that more likely than not parents were providing the sensitive responding and 'emotional availability' which is necessary for the development of secure attachments in the child. ${ }^{31} 32$ This was further supported by the finding that children with atopic eczema in our sample if anything were more securely attached than controls on the Ainsworth situation procedure. Mrazek et al found anxious resistant attachment relationships to be a feature of children with severe asthma, ${ }^{20}$ but unlike our sample, these children had had many admissions to hospital with the potential result that parenting had been severely disrupted.

There was a trend for children with atopic eczema to have more physical contact with their mothers during the attachment assessments. This may be related to the increased physical contact, which is an inherent part of the treatment of atopic eczema and is probably of no significance in terms of psychiatric adjustment as the subgroup of children who remained in constant physical contact with their mothers during the reunion episode were comparable with the rest in terms of behavioural problems. The specific area of parenting where mothers of children with eczema reported suboptimal functioning was discipline: fewer regarded this as effective and though being comparable with the control mothers in their use of strategies such as distraction, persuasion, ignoring, threats and punishments, they more commonly gave in to the child. It is a common but undocumented observation that parents often give in to the child to avoid conflict and their children's distress, which is likely to precipitate scratching and worsen the eczema. This may contribute to the increased emotional symptoms in the children by decreasing their chances to learn to cope with frustration and to develop a sense of mastery of the fears and separation anxieties that are developmentally common in preschool children. It may also underlie the parents' reports of poor behavioural adaptability. This suggests that it would be worth exploring the way in which the mother disciplines her child at the paediatric clinic, so that parents may be guided into using the most efficient method that can be successfully applied in children with atopic eczema.

We conclude that increased behavioural problems and parenting distress and difficulty are important features of severe atopic eczema in early childhood, but the indications are that the child's social development and the quality of the attachment relationship with the mother are not adversely affected and that the behaviour problems are probably temporary, related to the severity of the physical condition.

1 David TJ. Short stature in children with atopic eczema. Acta Derm Venereol (Stockh) 1989; 144 (suppl): 41-4.

2 Kristmundsdottir F, David TJ. Growth impairment in children with atopic eczema. $\mathcal{F} R$ Soc Med 1987; 80: 9-12. Golding J, Peters T. Eczema and hay fever. In: Golding J, ed. From birth to five. Oxford: Pergamon Press, 1986.

ed. From birth to five. Oxford: Pergamon Press, 1986 .
Her Majesty's Stationery Office. Morbidity statistics from general practice. London: HMSO, 1974.

5 Whittkower ED, Hunt BR. Psychological aspects of atopic dermatitis in children. Can Med Assoc $\mathcal{F}$ 1958; 79: $810-7$.

6 Cotterill JA. Psychiatry and the skin. Br f Hosp Med 1989; 42: 401-4.

7 Brown DG. Stress as a precipitant factor of eczema. f Psychosom Res 1972; 16: 321-7.

8 Koblenzer CS. Stress and the skin: significance of emotional factors in dermatology. Stress Medicine 1988; 4: 21-6.

9 Gil KM, Keefe FJ, Sampson HA, McCaskill CC, Rodin J, Crisson JE. The relation of stress and family environment 
to atopic dermatitis symptoms in children. $f$ Psychosom Res 1987; 31: 673-84.

10 Gil KM, Francis FR, Sampson HA, McCaskill CC, Rodin , Crisson JE. Observation of scratching behaviour in children with atopic dermatitis. Behaviour Therapy 1988 19: 213-27.

11 Allen KE, Harris FR. Elimination of a child's excessive scratching by training the mother in reinforcement procescratching by training the mother in reinfo

12 Melin I Frederiksen T, Noren P, Swebilius BG. Behaviour treatment of scratching in patients with atopic dermatitis. treatment of scratching in patients

13 Fritz G. Scratching inhibition in a child with hyper-ige syndrome. American fournal of Asthma and Allergy Pediatrics 1988; 2: 38-42.

14 Koblenzer CS, Koblenzer PJ. Chronic intractable atopic eczema. Arch Dermatol 1988; 124: 1673-7.

15 Richman N, Stevenson J, Graham PJ. Preschool to school: a behavioural study. London: Academic Press, 1982.

16 Richman N, Graham PJ. A behavioural screening questionnaire for use with three year old children. $f$ Child Psychol naire for use with three year
Psychiatry $1971 ; 12: 5-33$.

17 Richman N. Is a behaviour check-list for pre-school children useful? In: Graham PJ, ed. Epidemiological approaches in child psychiatry. New York: Academic Press, 1977: ????.

18 Ainsworth MDS, Wittig BA. Attachment and exploratory behaviour of one-year-olds in a strange situation. In: Foss BM, ed. Determinants of infant behaviour IV. London: Methuen, 1969

19 Van Ijzendoorn MH, Kroonenberg PM. Cross-cultural patterns of attachment: a meta-analysis of the strange situation. Child Dev 1988; 59: 147-56.

20 Mrazek DA, Casey B, Anderson I. Insecure attachment in severely asthmatic pre-school children: is it a risk factor? f Am Acad Child Adolesc Psychiatry 1987; 26: 516-20.

21 Quinton D, Rutter M. Parenting behaviour of mother raised 'in care'. In: Nicol AR, ed. Longitudinal studies in child psychology and psychiatry. Chichester: Wiley, 1985 157-201.

22 Newson J, Newson E. Patterns of infant care in an urban community. London: Allen and Unwin, 1963.

23 Newson J, Newson E. Four year olds in an urban community. London: Allen and Unwin, 1968.

24 Bailey D, Garralda ME. The use of social stress and support interview in families with deviant children: methodological issues. Social Psychiatry 1987; 22: 209-15.

25 Goldberg DP. Manual of the general health questionnaire. Windsor: NFER Publishing Company, 1978

26 Frankenburg WK, Dodds JB. The Denver development screening test. $f$ Pediatr 1967; 71: 181-91.

27 Office of Population Censuses and Surveys. Classification of occupations. London: HMSO, 1980.

28 Devlin J, David TJ, Stanton RHJ. Elemental diet for refractory atopic eczema. Arch Dis Child 1991; 66: 93-9.

29 Luk S-L, Leung PW-L Bacon-Stone J, et al. Behaviour disorder in pre-school children in Hong Kong: a two stage epidemiological study. Br $\mathcal{f}$ Psychiatry 1991; 158: 213-21.

30 Garralda ME, Reynolds JM, Jameson RA, Postlethwaite RJ. Psychiatric adjustment in children with chronic renal failure. I Child Psychol Psychiatry 1988; 29: 79-90.

31 Bowlby J. Attachment. London: Hogarth Press, Tavistock Institute, 1969.

32 Sroufe LA. Attachment classification from the perspective of infant-caregiver relationships and infant temperament. Child Dev 1985; 56: 1-14. 